\title{
AS TRÍADES E AS SOCIEDADES SECRETAS NA CHINA \\ Entre o mito e a desmistificação
}

\section{De Leon Petta}

Universidade de São Paulo (USP), São Paulo - SP, Brasil. E-mail: de.leon.petta@usp.br

DOI: $10.17666 / 329309 / 2017$

\section{Introdução}

Ao longo dos últimos cem anos, as tríades chinesas, principalmente em Hong Kong, foram cercadas por um imaginário místico e, às vezes, até mesmo romântico que lhes dá uma imagem de superorganização global centralizada, de modo similar àquela presente na ficção, o que está muito distante da realidade. Essa imagem conduz a erros que influenciam, de maneira negativa, o entendimento sobre o funcionamento do crime organizado e das sociedades secretas na China, o que pode comprometer tanto a precisão de pesquisadores como a elaboração de relatórios governamentais.

Pode-se dizer que essas distorçôes existem desde os primeiros relatos ocidentais sobre as tríades chinesas, ainda no século XIX, os quais, geralmente,

Artigo recebido em 17/11/2015

Aprovado em 17/10/2016 eram elaborados por maçons britânicos. Por isso a análise era revestida de características místicas e esotéricas, pois sentiam que essas sociedades eram semelhantes à sua própria organização. Somente com o tempo as autoridades britânicas, na ainda colônia de Hong Kong, passaram a criminalizá-las, em virtude dos problemas que elas representavam para a administração colonial, com eventuais insurgências na regiáo dos mares do Sul da China. Décadas mais tarde, isso levou a uma associação equivocada entre tais sociedades - as tríades - e as facções ligadas ao crime organizado, ou seja, considerava-se que o crime organizado chinês era essencialmente composto por membros das tríades. ${ }^{1}$

Por estarem presentes na região, as autoridades britânicas em Hong Kong foram por muitas décadas as únicas que fizeram referência a e escreveram sobre as sociedades secretas chinesas. Em consequência, as tríades tornaram-se a sociedade secreta mais estudada e difundida no mundo, o que levou ao segundo erro 
de interpretação: de que toda a criminalidade organizada composta por chineses é, necessariamente, uma facção tríade. Mas o fenômeno está geograficamente limitado à região de Guangdong (no sul da China) e aos territórios banhados pelo mar do Sul da China (Hong Kong, Macau, Indonésia, Tailândia, Cingapura etc.). Na região continental da China, assim como nas comunidades de imigrantes chineses em outros países, há sociedades secretas e facçôes criminosas que são totalmente diferentes das tríades, em termos de origem, organização, estrutura, campo de atuação, nível de agressividade e relação político-social.

O terceiro equívoco diz respeito à organização e à estrutura das tríades. Associadas frequentemente à Yakuza e à antiga máfia ítalo-americana (de caráter estritamente hierárquico), as tríades passaram por sucessivas remodelagens estruturais depois década de 1970 , e pouco a pouco deixaram de ter uma composição piramidal rígida para funcionar mais como redes planas, com níveis de acesso e contato não necessariamente hierárquicos. Passaram, a partir daí, a se concentrar mais em atividades lícitas que ilícitas, como estratégia de sobrevivência à repressão, primeiro, das autoridades coloniais britânicas e portuguesas, em Hong Kong e Macau, e, depois, do governo chinês, quando da retomada dessas cidades nos anos de 1990.

Por fim, a quarta confusão decorre da ideia de que existe apenas uma tríade chinesa, quando, na verdade, existem várias dezenas de tríades chinesas, as quais constituem ramificaçóes a partir de um núcleo comum, que, após a fundação da República da China, passaram a disputar espaço de atuação no país e também em outros países da Ásia.

Esta pesquisa foi conduzida no Centro de Criminologia da Universidade de Hong Kong. Com extensa pesquisa bibliográfica e realização de entrevistas com pessoas ligadas de alguma forma à temática das tríades chinesas e do crime organizado na Ásia - acadêmicos de Hong Kong, Macau e Estados Unidos, ${ }^{2}$ jornalistas, policiais e até mesmo membros das tríades -, o foco da pesquisa incidiu na geografia e na antropologia dessas sociedades secretas, para além de questóes unicamente criminológicas.

Como se trata de um tema que exige certa cautela, foi necessário fazer um acordo para a realização das entrevistas: cada entrevistado foi identificado e recebeu um roteiro antecipado para sua aprovação. Dessa maneira, compilaram-se sete entrevistas. Em casos que envolviam pessoas mais diretamente ligadas às organizações, a identificação não foi possível, pois comprometeria os contatos pessoais, inclusive com brasileiros, que viabilizaram a observação de campo.

\section{Origem e simbolismo}

As mais antigas informaçóes trazidas ao Ocidente podem ser encontradas em livros, geralmente esotéricos, escritos por diplomatas britânicos e oficiais militares (policiais), como Herbert A. Giles (2000), e sacerdotes europeus, como John Sebastian Marlowe Ward (2000), ambos maçons, o que provavelmente marcou esses trabalhos, envolvendo todo o imaginário simbólico desses observadores.

Algumas dessas primeiras obras identificaram essas sociedades secretas chinesas, em especial as tríades, como uma espécie de maçonaria chinesa não da forma como a maçonaria se apresenta no Ocidente, mas com perspectivas esotéricas bastante similares, a exemplo da ideia do "Grande Arquiteto" (P'an-Ku para os chineses) e outras tradiçóes cerimonialistas de origem confuciana. Giles (2000), em 1880, ao analisar várias escrituras de Confúcio e Mêncio, selecionou pontos similares entre essas organizações e a maçonaria, como o padrão moral, os símbolos, credos e cerimônias, assinalando que até mesmo o nome original das tríades teria uma origem sagrada e mitológica, "a Sociedade do Céu, da Terra e do Homem” (Ward, 2000).

Outra revisão sobre a origem das tríades chinesas vem de William Stanton (2000), um oficial de polícia britânico que atuou em Hong Kong por volta de 1900. De acordo com ele, essas sociedades secretas (não necessariamente as tríades) originárias da China poderiam ter sua origem rastreada desde tempos remotos, citando os exemplos dos Turbantes Amarelos ${ }^{3}$ durante a dinastia Han (184 d.C.), da Sociedade do Lótus Branco durante a usurpação de Wang Mang (9 d.C.) e das rebelióes da administração mongol, na dinastia Yuan (1271 d.C.). Ainda de acordo com Stanton (2000), na- 
quela época (nos anos de 1900), vários pesquisadores relacionavam a Sociedade do Lótus Branco às tríades, associação equivocada pelo fato de serem organizaçóes diferentes e independentes entre si. As tríades seriam mais recentes, tendo surgido apenas no século XVII, já que tinham como berço a resistência chinesa contra a invasão de povos oriundos da Manchúria.

Os manchus (que posteriormente iriam fundar a dinastia Qing) fizeram diversas incursões militares onde ainda havia focos de resistência e também líderes da dinastia Ming. Estes, por sua vez, refugiaram-se em um monastério em uma região montanhosa, de onde, após sucessivas batalhas, os sobreviventes (conhecidos como "pais fundadores") fugiram e fundaram o que viria a ser as tríades. Esses insurgentes tinham, no cerne de sua luta, a resistência contra a opressão, promovida pelos oficiais manchus, usando o lema "Derrubar Ch'ing, restaurar Ming”. Na fuga, apenas cinco monges teriam sobrevivido, fundando então a Associação do Céu e da Terra (Stanton, 2000; Nash, 2004, p. 1464) ou Tiandihui. ${ }^{4}$

J. S. M. Ward (2000) relaciona a origem das tríades aos aspectos ainda mais antigos. De acordo com o autor, durante a Rebelião dos Turbantes Amarelos, três guerreiros se destacaram e ganharam proeminência nos combates: Liu Pei (Liu Bei), Kwan Yi (Guan Yu) e Chang Fei (Zhang Fei). Esses três grandes guerreiros se encontraram certo dia em um jardim de pessegueiros, acenderam um incenso mágico e seguiram com um ritual, no qual sacrificaram um touro negro e um cavalo branco, ofereceram oraçôes às divindades antigas e vincularam-se um ao outro em um juramento de fidelidade especial. Essa cerimônia representaria as forças naturais e as forças de oposição, como o dia e a noite, e a partir dela as tríades surgiriam. Ward (2000) também aponta que essa organizaçáo seria uma força que, frequentemente, se rebelava contra os governos tirânicos e contra invasores estrangeiros.

W. P. Morgan (2000), um antigo inspetor da polícia real de Hong Kong, também ilustra o quão profunda e importante é a influência do taoísmo e do confucionismo para as sociedades das tríades. No entanto, nesse caso, o autor aponta as tríades como um dos vários braços da Sociedade do Lótus
Branco, sendo específicas da regiáo sul da China, e aponta a Sociedade Ching Pang como um outro braço, situado na regiáo norte, considerado nacionalista e muito mais antigo que as tríades, pois teria sua origem no ano de 200 a.C. (Ward, 2000; Morgan, 2000). Outros autores como Chesneaux, referem-se a ambas as sociedades como se fossem completamente distintas.

No caso dessa especificidade geográfica apontada por Morgan (2000), ainda que o artigo tenha sido escrito em 1960, os apontamentos ali expostos foram corroborados pelas entrevistas realizadas durante o estágio, momento em que tanto o professor da Universidade de Hong Hong como o ex-superintendente da polícia de Hong Kong, além de outras fontes diretas e informais, confirmaram que as tríades no passado atuavam em pequena escala dentro da China continental e que sua grande base de operaçóes foi a região sul chinesa, sobretudo Hong Kong, estendendo-se para Guangdong, Macau, Taiwan e até outros países banhados pelos mares do Sul da China, tais como a Indonésia, Tailândia, Malásia e Cingapura (sendo esta última considerada, hoje em dia, uma base operacional das tríades chinesas ainda mais ativa do que Hong Kong). A identidade geográfica das tríades com a região de Hong Kong e os territórios localizados nos mares do Sul se aprofundara apenas após a perseguição comunista contra as sociedades secretas chinesas iniciadas por Mao Tsé Tung. Isso fez com que as tríades cessassem temporariamente suas operaçóes na região continental e se refugiassem no além-mar, sobretudo em Hong Kong e Taiwan.

De qualquer forma, é difícil dizer se essas pesquisas representam uma imagem precisa dos períodos mais remotos das tríades, uma vez que relatórios e estudos posteriores demonstraam uma perspectiva diferente dessas antigas imagens e mitos. Além disso, essas análises carregavam uma profunda carga mitológica e romântica acerca dessas sociedades, principalmente pelo fato de que a maioria desses autores também faziam parte de alguma organização esotérica, como a maçonaria. Situando-se entre mitologia e vida real, elas encontraram na colônia britânica de Hong Kong uma região estratégica e acolhedora para manter suas operaçóes. 
A população crescente e a gigantesca disparidade econômica e social criaram lugares como a Cidade Murada de Kowloon, uma grande espécie de cortiço vertical, com uma enorme aglomeração de pessoas apertadas, em uma área de apenas 2,7 hectares (27 mil metros quadrados), um local que, exceto em casos de emergência militar, estava fora da jurisdição das autoridades coloniais. Sem qualquer acesso aos serviços sociais, as tríades providenciavam seus serviços privados, contando com dentistas, médicos, fitoterapeutas, eletricistas etc. Ademais, a posição privilegiada de Hong Kong, com seu imenso e extremamente importante porto, dava aos criminosos meios de obter os mais variados contrabandos, sobretudo o ópio, além de rotas na região do Sul e Sudeste asiáticos, espalhando as operaçóes das tríades em vários outros países da região, como Cingapura, Malásia, Índia, Indonésia e até Estados Unidos e Austrália. O número de tríades aumentaria drasticamente na virada do século XIX para o XX, com a população de imigrantes que afluiu a Hong Kong (Liu, 2003, p. 10).

O que é factual nas tríades é que todas elas possuem uma origem em comum, a Sociedade Hung Mun. Essa sociedade era, originalmente no século XIX, baseada em preceitos morais e de lealdade, como uma maciça e extremamente coordenada organização política e militar, com uma cadeia de comando estruturada que contava com oficiais de diferentes graus e seguidores. Porém, quando a China se tornou uma república, em 1911, a Sociedade Hung Mun fragmentou-se em dezenas de sociedades menores, cada qual buscando seus próprios interesses. Entre essas sociedades menores, as mais conhecidas são a $14 \mathrm{~K}$ e a Sun Yee On (Lo e Kwok, 2013a).

Ademais, as tríades e outras sociedades secretas possuem a tradição de servirem como "aluguel de músculos" e serviços para provocar tumultos e rebelióes, os quais causavam profundos danos aos governos que não negociavam com elas. Um exemplo é a rebelião taiwanesa de Lin Zhong, em 1789, que custou para a corte local um terço de seus rendimentos anuais. Em outra ocasião, já em 1930, o chefe das "Cinco Montanhas Sagradas", Mau Ting Fong, foi promovido a tenente-general do Partido Republicano, o Kuo Min Tang (KMT). De fato, quase todas as rebelióes e revoltas na região sul da China estavam conectadas com a insatisfação dos membros das tríades, sendo que algumas vezes essas desordens requeriam até mesmo operações conjuntas entre forças chinesas e britânicas para a pacificação, tamanha a capacidade de mobilização que tais organizaçóes podiam despender quando lhes fosse interessante.

Outro notório exemplo se deu em 1895, quando Sun Yat Sen (considerado o pai da república chinesa) também empregou membros das tríades nas revoltas de Guangzhou (afinal, ele mesmo era um reconhecido tríade). Essa disponibilidade e habilidade também foram reconhecidas pelas forças de ocupação japonesas durante a Segunda Guerra Mundial, que contrataram algumas das tríades locais para controlar a populaçáo local e lutar contra eventuais guerrilheiros na região de Hong Kong e no sul da China5 (Liu, 2003, p. 36).

Os tentáculos das tríades chinesas se expandiram para os países do mar do Sul da China muito antes do período contemporâneo, tendo sua presença em diversos países da região. Segundo Comber (2009), as sociedades secretas chinesas na Malásia não apenas são descendentes das tríades, mas sua denominação de Sociedade Han Liu é um alias dictus (anagrama) para Sociedade das Tríades. Além disso, outras sociedades secretas chinesas na região (algumas tidas como extintas), como a Sam Hap Hoey (Sociedade União dos Três), a Liga Hung (Sociedade da Inundação) e a Sociedade da Água Pura, escondem ideogramas que mostram que na verdade seriam todas tríades chinesas disfarçadas, mudando, ocasionalmente, apenas de nome para confundir as autoridades locais.

\section{As atuais operaçóes das tríades em Hong Kong, Macau e Taiwan}

É correto afirmar que há ao menos três bases operacionais principais das tríades, sendo elas Hong Kong, Macau e Taiwan ${ }^{6}$ (com fortes indica çóes de uma quarta, em Cingapura, igualmente importante), com sucursais de atuação no restante dos países dos mares do Sul da China (Tailândia, Indonésia, Vietná, Malásia, Filipinas e Camboja). 
Outros países, como os Estados Unidos, Japão, Austrália, Inglaterra, França, Costa Rica e até mesmo o Brasil, eventualmente, também teriam a atuação das tríades, contudo, de forma mais pontual e restrita. Embora seja importante afirmar que outras sociedades secretas ou facções criminosas chinesas podem atuar no além-mar, por vezes é errôneo associá-las às tríades. Apesar disso, o termo "tríades chinesas" tem sido sistematicamente usado no Ocidente para generalizar qualquer gangue ou grupo criminoso composto por pessoas de origem chinesa. A difusão dessa premissa errada foi causada sobretudo por acadêmicos e pelos relatórios dos Estados Unidos, os quais acabam por servir de fonte para outros pesquisadores ao redor do mundo .

O ano de 1997, com a volta de Hong Kong para a China, marca um importante divisor de águas na atuação das tríades chinesas na região. Até então, as mais diversas fontes (inclusive relatórios de governos) apontavam a possibilidade de um gigantesco êxodo das tríades com base em Hong Kong para o exterior, fugindo da administração do Partido Comunista Chinês sobre a cidade e expandindo suas ideias para os mais diversos países ao redor do mundo; porém, isso não ocorreu.

A prosperidade econômica em Hong Kong e na região ao redor propiciou um sensível aumento na demanda de bens e serviços (lícitos e ilícitos) que foi sabiamente explorada pelas tríades e gangues locais. $\mathrm{Na}$ verdade, as tríades já haviam desenvolvido grandes habilidades para extrair diversas oportunidades de negócios após as reformas econômicas chinesas, nos anos de 1980, contrabandeando todos os tipos de produtos para a China continental e servindo como uma ponte de interação informal entre o continente e Hong Kong, que contava com uma logística transfronteiriça altamente sofisticada, ampliada com o tempo em virtude do relaxamento das fronteiras após a reintegração.

Essas redes de contatos, estabelecidas ao longo das décadas entre as tríades e os grupos criminosos da China, na região de Guangdong passaram a ser mais abertamente exploradas pelos mais diversos grupos das tríades, contratando criminosos dentro da China para atuarem nos mais diversos delitos na região, desde contratos para assassinatos até assaltos e sequestros. Assim, os membros das tríades con- seguiram manusear essa retomada de Hong Kong para a China como uma forma de investimento, colaborando com os criminosos continentais para auxiliá-los na distribuição de drogas dentro da China (Laidler et al., 2000; Lo e Kwok, 2012).

Ainda durante os anos de 1990, a guerra entre os diferentes grupos de tríades, as disputas internas e a pressão da polícia de Hong Kong criaram um processo gradual de desorganização das facçóes, gerando diversas e menores células, vagamente organizadas e cada vez menos centralizadas. Com isso, as promoçóes e o recrutamento não seriam mais determinados por um núcleo centralizado e os chefes não teriam mais contato absoluto e direto sobre as subdivisóes dessas organizaçôes. Assim, os grupos das tríades se adaptaram e se reagruparam em cartéis não centralizados ou nucleares, contendo diversas gangues independentes, as quais adotaram apenas a estrutura organizacional e os rituais para manter os membros unidos entre si (Chu, 2005).

Além disso, por causa das transiçóes econômicas, sociais e políticas, os membros das tríades mudaram seu caráter criminal para um caráter mais empresarial, uma nova estratégia para sobreviverem nesse novo cenário. Como uma empresa comum, suas decisôes foram então direcionadas para minimizar os custos e os riscos e maximizar os lucros e os benefícios. Nesse sentido, se os fins não justificarem os meios, os membros das tríades evitarão atuar de forma criminosa. A rede de contato das tríades, desse modo, mistura cada vez mais o lícito com o ilícito (Lo e Kwok, 2012).

O que se demonstra é que, longe de as tríades comporem a velha e tradicional estrutura piramidal, sua organização atualmente é baseada em redes de contatos que prestam variados serviços, sendo que nem todos os membros das tríades chinesas são necessariamente relacionados com o crime organizado ou com atividades ilícitas, assim como nem todos os grupos criminosos compostos por chineses são integrantes das tríades. ${ }^{7}$

De fato, organizações criminosas não subsistem exclusivamente pelas suas atividades criminosas, necessitando de certo espectro de legitimidade e variando o grau de atividade criminal em suas ações. Uma vez que sua economia é baseada na zona de transiçáo entre o legal e o ilegal, é neces- 
sário que parte de seus ganhos seja lícita, para que os lucros obtidos ilegalmente sejam lavados através desses empreendimentos de fachada (Albanese, 2007, pp. 5 e 296). Porém, a diferença entre as tríades e as organizaçóes criminosas convencionais se dá na dimensão de suas atividades. Enquanto as organizaçóes criminosas utilizam as atividades legais apenas para a lavagem de dinheiro ou como complemento, uma vez que praticamente todo o seu lucro provém da prática ilícita, as tríades chinesas obtêm a maior parte de seu lucro por meio de negócios lícitos, os quais são construídos e moldados pelo capital social ${ }^{8}$ que os membros da facçáo desenvolvem, contando com a rede de contatos que a organização proporciona. Nesse sentido, o lucro proveniente da atividade criminal náo é o principal, mas um complemento marginal obtido por alguns membros das tríades.

Outra região cada vez mais importante de atuação das tríades é Macau, onde há muito tempo há problemas transfronteiriços com a presença de organizaçóes criminosas estrangeiras atuando na cidade; não apenas de membros das tríades chinesas, mas gangues fortemente armadas oriundas da China, que atacam os cassinos macaenses, redes utilizadas para o tráfico sexual de outros países asiáticos, lavagem de dinheiro, tráfico de armas e drogas por parte de autoridades norte-coreanas.

Após a retomada de Macau por parte da China (1999), as tríades aumentaram sua participação na economia da cidade, elevando os seus investimentos e o gerenciamento na indústria de cassinos, até então controlada pelo magnata local Stanley Ho em parceria com as autoridades portuguesas coloniais. Isso desencadeou uma longa guerra entre os diferentes grupos de tríades na regiâo. Essa tentativa de infiltração é algo recente e configura a disputa de poder em Macau e na indústria de cassinos, uma vez que Stanley Ho conseguiu , junto com as autoridades portuguesas coloniais, manter Macau limitada à influência das tríades por muitos anos (Lo, 2009, p. 131).

Apesar do destaque de Hong Kong e de Macau como "quartéis-generais" das tríades, Taiwan possui com elas uma relação mais profunda e complexa do que as primeiras duas cidades. Em Taiwan, as tríades não agem de forma secreta, mas configuram parte do poder político e público da ilha. No final dos anos de 1980, as tríades Bambo Unido (Zhūliánbāng) e Quatro Mares (Si Hai Bang) passaram a atuar mais como organizaçóes políticas quase similares aos partidos - do que, necessariamente, como facçôes criminosas. Esse modo de atuação emergiu para disputar o poder e a influência sobre a política taiwanesa, como uma forma de sobreviver à tentativa de criminalização que as tríades vinham sofrendo (Chin, 2003, p. 7).

Essa relação é ainda problemática em virtude da ligação antiga que as tríades possuem com o complexo de Defesa e Inteligência de Taiwan, pois, ao final da Segunda Guerra Mundial e com o início da Guerra Civil chinesa, Chiang Kai-Shek ${ }^{9}$ recrutou sistematicamente forças compostas por tríades para lutar contra o exército comunista de Mao Tsé-Tung, empregando muitos dos líderes das tríades no quadro do governo de Taiwan. ${ }^{10}$ Essa relaçáo ficou ainda mais evidente nos anos de 1980, quando o jornalista Henry Liu, agente triplo que atuava como espiáo tanto para o governo taiwanês, quanto para o chinês e norte-americano, foi descoberto, fugindo para a Califórnia, nos Estados Unidos, onde julgou que estaria protegido do governo de Taiwan. Contudo, foi executado por membros de tríades a mando do KMT em 1984 (Kaplan, 1992), o que provocou uma forte crise diplomática entre os Estados Unidos e Taiwan, agravada ainda mais pelo fato de a CIA saber do plano antecipadamente e não comunicar ao FBI.

Além de Macau, Hong Kong e Taiwan, outros países banhados pelos mares do Sul da China, como Malásia, Tailândia, Cingapura, Indonésia, entre outros, também têm sido área de atuação clássica das tríades chinesas. Nesse sentido, é errôneo apontar como expansão o efeito da globalização pós-Guerra Fria. A atuação das tríades, nos países dessa região, ocorre de forma bastante antiga e profunda, obrigando as antigas autoridades coloniais europeias a terem algum tipo de negociação com os líderes das tríades, não apenas para evitar rebelióes, mas também para auxiliá-los na administração colonial sobre as populaçôes de imigrantes de origem étnica chinesa nos países da região. Ocasionalmente, quando diferentes facçóes dessas sociedades lutavam entre si, o conflito tomava proporção tamanha 
que requeria o uso de forças armadas para intervir e pacificá-las, como foi o caso dos Tumultos de Penang, em 1867, envolvendo 30 mil chineses e 4 mil indianos e malaios. Foi um conflito entre as sociedades secretas locais que obrigaram até mesmo o exército inglês a se retirar da região e aguardar o desfecho do conflito para, entáo, com maciços reforços vindos de Cingapura, tentar pacificar a área (Comber, 2009, p. 1).

As tríades e outras sociedades secretas chinesas (tais como os Tongs) não se expandiram para diversas regióes do globo em virtude do que seria o processo de globalização pós-Guerra Fria. Essas sociedades secretas haviam se expandido nas diversas as comunidades chinesas no exterior - as Chinatowns - das grandes cidades já no século XIX. Nessas sociedades, sempre foi possível notar grande resiliência e adaptabilidade de seus membros para sobreviver, como ficou demonstrado no curioso caso após as Guerras do Ópio. ${ }^{11} \mathrm{O}$ governo imperial chinês havia proibido o consumo de ópio desde 1729; contudo, companhias inglesas e norte-americanas constantemente enviavam remessas ilegais da substância para a China, por meio de contrabandistas, ignorando de forma aberta as leis chinesas antiópio. Com o tempo, as tensóes entre o Império da China e o Império Britânico acerca do tráfico de drogas desencadearam a Primeira Guerra do Ópio, quando oficiais chineses apreenderam e destruíram cargas de opiáceos. Para a Inglaterra, aquele ato hostil requereria uma reparação por danos materiais; foi então declarada guerra contra a China, posteriormente vencida pelos ingleses. $\mathrm{O}$ resultado foi a cessão de Hong Kong e o pagamento de indenização para a Inglaterra, além do mais importante: o aceite do governo chinês em liberar o consumo do ópio dentro da China. ${ }^{12}$

A ideia do governo inglês era fazer com que as balanças comerciais entre China e Inglaterra pendessem para os ingleses, uma vez que há muito tempo o comércio era extremamente favorável à China, que quase nada importava de outros países, e o ópio (produzido na Índia colonial, pelos ingleses), por sua vez, era o único produto que os ingleses conseguiam vender em larga escala para os chineses. Assim, o fim do proibicionismo e a vasta densidade demográfica chinesa, supostamente, sig- nificariam uma explosão de novos consumidores, o que de fato aconteceu dentro de um curto prazo.

As rotas do ópio a partir de Hong Kong, que forneceram a toda a China 6500 toneladas de ópio em 1880, ingressaram no mercado chinês e passaram a abastecê-lo. No entanto, com o tempo, as sociedades chinesas do interior do território chinês também começaram a produzir o ópio e, nos anos seguintes, a venda desse produto para a China, que gerava a imensa receita para a Inglaterra, começou a cair drasticamente, em função da produção doméstica chinesa. A China, que era a maior consumidora de ópio no mundo, na virada do século XIX para o XX tornou-se produtora e exportadora de 22 mil toneladas (Lintner, 2002, p. 27), abastecendo o tráfico de drogas em todo o mundo, sobretudo no Japão, nos Estados Unidos e na Europa, através de redes estabelecidas nas Chinatowns das principais cidades do mundo, onde a distribuição era feita em parceria com as gangues locais. ${ }^{13}$

\section{O funcionamento e a estrutura das tríades chinesas}

Um dos grandes problemas relacionados com as tríades é a abordagem genérica sobre o tema, como se as tríades fossem uma espécie de "máfia chinesa”, o que incorre em dois erros. O primeiro, já citado, é generalizar qualquer grupo criminoso como se fosse tríade, apesar de as tríades serem um fenômeno específico da regiāo do sul da China; esse erro é extensivamente repetido, principalmente, na literatura norte-americana. O segundo equívoco é o de que as tríades, em si, são uma facção criminosa. Diferente disso, as tríades são sociedades secretas, com várias facçóes, nas quais parte de seus membros está relacionada com atividades ilícitas, enquanto outra parte não, pois se trata muito mais de uma rede de contatos do que de uma organização apenas para fins criminosos. Essa rede de contatos acaba por incluir membros de gangues ou criminosos especializados, mas também empresários, políticos, artistas, atletas, acadêmicos, funcionários públicos etc., os quais, excluindo o fato de se conhecerem, não poderiam ser indiciados por atividade ilícita. 
Essa moderada e relativa descentralização e hierarquização se devem, basicamente, às fortes atuaçôes das autoridades de Hong Kong contra a influência das tríades na cidade, entre elas a criação da Independent Commission Against Corruption (Icac), uma instituição responsável pelo combate à corrupção de qualquer característica e nível na cidade de Hong Kong. Outro fato, destacado pelos policiais veteranos, também diz respeito às operações antitríades, as quais, em sua maioria, eram realizadas pela polícia convencional, pouco preparada para engajamentos táticos em caso de combates com maior intensidade. Isso levou, posteriormente, à utilização da Divisão Antiterrorista ${ }^{14}$ nas operaçóes especiais, munida dos melhores equipamentos e do melhor treinamento para combates táticos.

A destruição das "favelas" e cortiços, como a cidade murada de Kowloon (territórios de ampla influência das tríades), e sua substituição por diversas moradias populares também fizeram parte do avanço social, no que se refere ao processo de desenvolvimento urbano da cidade. Esse avanço em várias frentes, contra a influência das tríades na cidade, obrigou-as a um novo ajustamento de suas operaçóes caso decidissem sobreviver, afastando-se cada vez mais da imagem da criminalidade violenta para assumir características mais empresariais, relacionadas aos crimes de "colarinho branco" ou redes de contato e influência.

Todavia, um dos maiores golpes contra as tríades foi de caráter simbólico, no que concerne à organização, decorrendo do fato de a própria associação com as tríades passar a ser considerada crime. De acordo com Lo e Kwok (2013a), o fato de alguém se autodenominar membro de uma tríade ou mesmo carregar símbolos que remetam a essas sociedades passou a ser suficiente para obter a sua condenação, mesmo que não haja qualquer evidência de envolvimento em atividades ilícitas. Desse modo, ser membro ou estar associado a alguma tríade, por si só, é passível de criminalização, o que afetou todo o caráter tradicional da organização, inclusive a entrada na sociedade, pois estar presente durante os rituais cerimoniais $^{15}$ seria o bastante para que houvesse a acusação de associação com as tríades (Idem, 2013a).

De acordo com membros policiais entrevistados, como um ex-superintendente, isso fez com que os rituais deixassem de existir nos dias de hoje, constituindo, a partir de então, o imaginário romântico e cinematográfico ${ }^{16}$ ou ocidental em relação às tríades, tais como as descritas por Booth ou Abadinsky, ${ }^{17}$ que as comparam com a Yakuza ou com uma organização secreta, com apertos de mãos secretos, emblemas, burocracias e tradiçôes, além de cerimônias, como as queimas de incenso e as oraçōes (Booth, 1999, p. 160; Abadinsky, 2010, p. 221). Contudo, de acordo com acadêmicos e tríades, os rituais apenas passaram a ser raros, mais enxutos e curtos, dado o receio de que, eventualmente, policiais infiltrados estivessem presentes e pudessem testemunhar em futuros processos.

Outro ponto importante a ressaltar é o fato de que as diferentes tríades possuem diferentes formas de organização estrutural. A maior delas, a $14 \mathrm{~K}$, é bastante descentralizada e possui uma hierarquia não muito bem definida, enquanto a Sun Yee On ainda mantém uma estrutura mais centralizada (embora muito longe do que fora no passado) e organizada. Outras tríades (há dezenas apenas em Hong Kong) apresentam modelos diversos de organização.

De modo geral, o que diferencia as tríades de outras organizaçóes e sociedades é a sua origem, a qual está baseada na territorialidade ou na posição geográfica específica, na composição étnica (predominantemente chinesa, da etnia Hakka, embora haja outras etnias em menor escala), na simbologia (há fortes elementos confucianos e taoístas), na ritualística esotérica e no modus operandi de uma sociedade estruturada por meio de redes de contato, não necessariamente voltadas integralmente ao crime. Aliás, alguns membros das tríades entrevistados gostam de atribuir a si a imagem de defensores de valores tradicionais, culturais e mitológicos do sul da China, o que remeteria a uma identidade nacionalista. Contudo, é difícil dizer o grau desse comprometimento ou se é uma mera retórica para justificar suas atividades.

A capacidade de adaptação e transformação das tríades, bem como de outras sociedades secretas, pode ser constatada nas seguintes figuras, as quais mostram que, de modo diferente da ideia de uma estrutura piramidal ou de uma hierarquia rígida, as tríades chinesas têm migrado para um modelo mais plano, com diferentes níveis de acesso. 
Figura 1

\section{Estrutura Original das Tríades.}

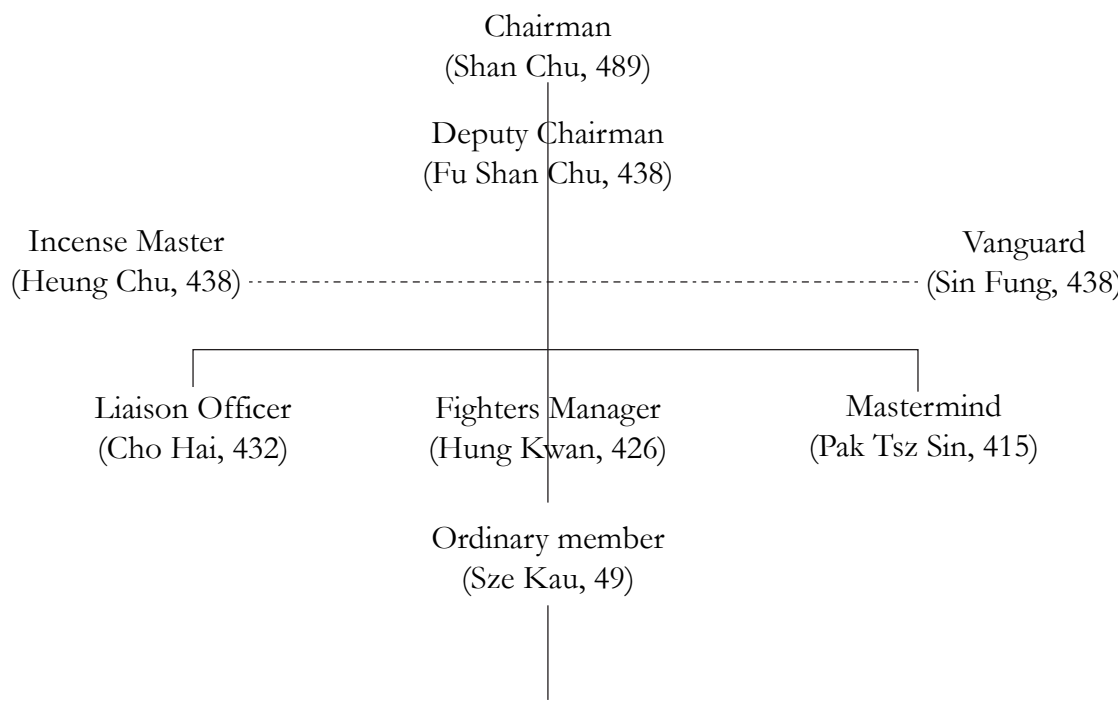

Affiliated member

(Hanging the Blue Lantern)

Fonte: Lo e Kwok (2012, p. 5334).

\section{Figura 2}

Estrutura das Tríades, em 1998, Divididas em Células.
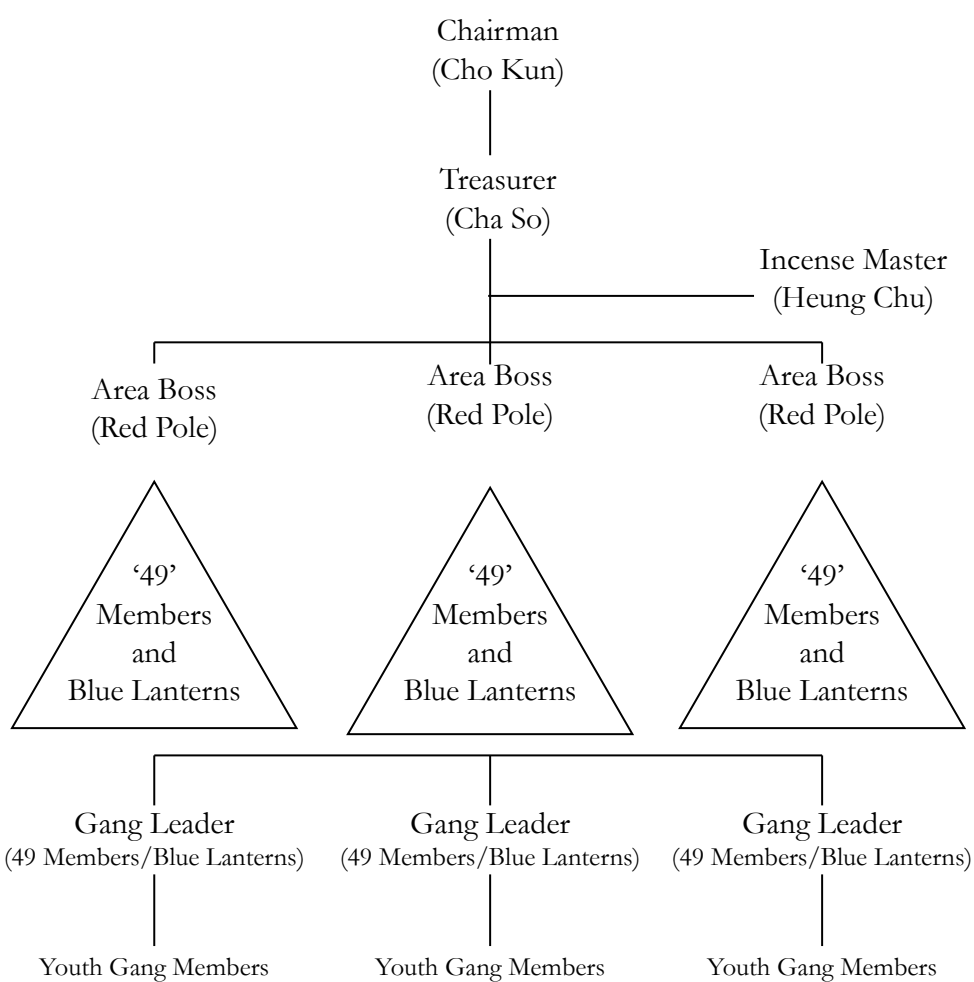

Fonte: Chu (2000, p. 28). 
Figura 3

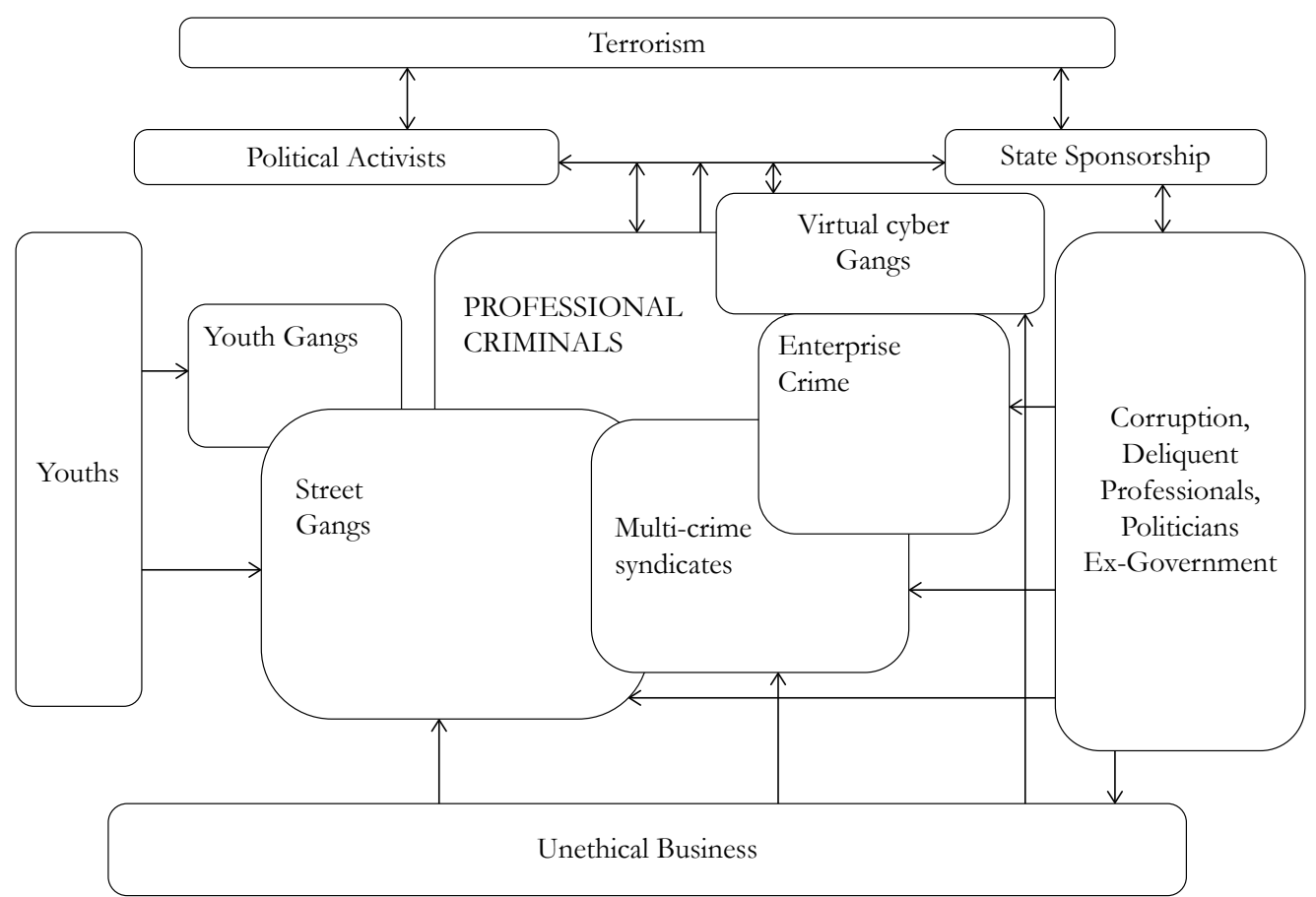

Fonte: Tabela cedida gentilmente por David Hodson, ex-superintendente da Polícia de Hong Kong, chefe das divisóes antitríades e antidrogas, que ilustra como se configuravam as tríades em 2015.

É interessante observar que, em 1998, a estrutura das tríades já passava pelo processo de descentralização e subdivisão, para que pudessem atuar por meio de diversas células menores, uma mutação em andamento desde o final da década de 1970, chegando ao que hoje seria considerado um ambiente mais plano, cuja única divisão é baseada em camadas de acesso e especialidades. De fato, há um controle das tríades sobre parte da criminalidade na regiáo de Hong Kong, Macau e Taiwan, que é feito, porém, por canais indiretos, os quais dificilmente poderiam comprometer toda a estrutura com as atividades ilícitas. Além disso, se um membro de um grupo criminoso ou gangue faz parte das tríades não significa que todo o seu grupo também faça. Geralmente, apenas os líderes dessas tríades é que são convidadas a participar em troca de proteção de uma estrutura de poder social maior.

Outro ponto importante a se levantar diz respeito à etnia dessas sociedades, pois diferentes tríades têm diferentes rigores quanto à origem étnica requerida para participar de sua rede. Originalmente, houve a determinação de que seus membros tivessem origem chinesa, cantonesa, hakka e chaouzho (Haar, 1998 , p. 15), o que era uma forma de evitar infiltraçóes por parte de agentes e autoridades de Pequim ou do governo colonial britânico. Contudo, após algumas décadas, essa determinação ficou menos rígida, em virtude principalmente de essas questóes étnicas gradualmente se diluírem à medida que a imigração mudou as características étnicas ao longo do século XX em Hong Kong, Macau, Taiwan etc.

Embora a composiçáo das tríades ainda seja, majoritariamente, de chineses dos grupos citados, é possível encontrar outras etnias chinesas, como tibetanos, além de outros grupos não chineses, como nepaleses, paquistaneses, tailandeses e alguns raros ocidentais. ${ }^{18}$ A origem nacional e racial dos membros das tríades é um fator determinante para se ganhar a confiança nessas sociedades. Durante toda a realizaçáo da pesquisa, por exemplo, todas as fontes consultadas deixaram bastante claro que britânicos, franceses ou norte-americanos (que não sejam de origem chinesa) não se tornariam tríades, fato que não impede que eles colaborem com as tríades em algum nível similar ao de "coassociado". 


\section{Figura 4 \\ Mapa Mostrando a Regiáo Sul da China e o Sudeste Asiático}

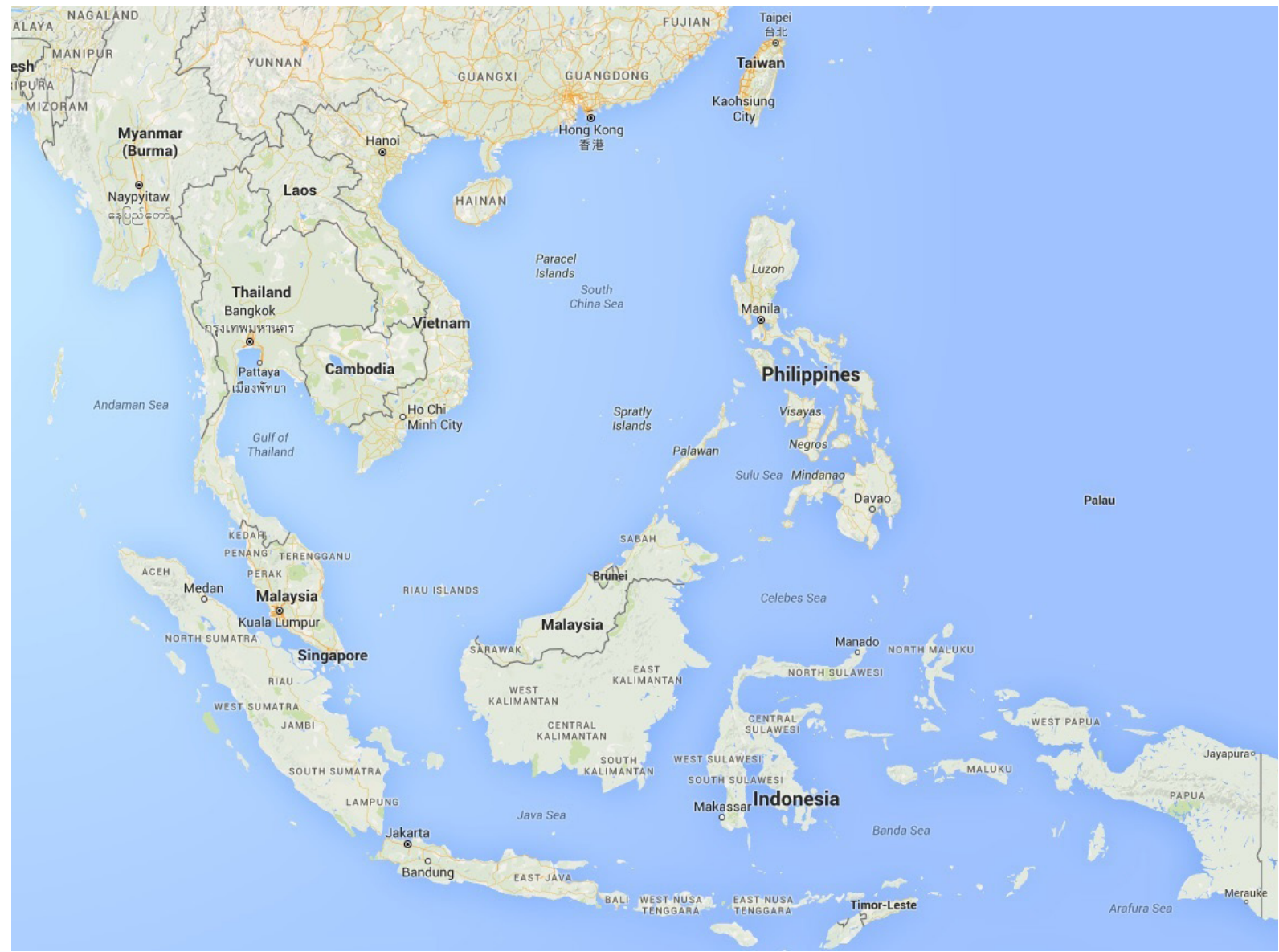

Fonte: Google Earth (2016).

\section{Outras sociedades, organizaçóes e grupos}

Um dos fatores que caracterizam as tríades chinesas é a sua territorialidade, cujas bases estão na região do mar do sul da China, com operaçóes pontuais em regiôes além-mar. Outras sociedades dentro da China e as comunidades chinesas no exterior apresentam outras características, além do perfil geográfico: o método de operação, a estrutura de funcionamento, a atuação de mercado, o comportamento social, a área de abrangência etc.

Um exemplo importante de organização paralela às tríades são os Tongs, também originados em Hong Kong, mas fundados por pessoas que seriam vítimas dos assédios das tríades e que, com o passar do tempo, ampliaram o seu poder sobre as
Chinatowns. Tal como outras sociedades chinesas, os Tongs também atuam no limiar da ilegalidade, exercem atividades legais e sociais, em alguns casos fazem a interlocução entre a população imigrante chinesa e as autoridades locais, mediam os conflitos internos nas comunidades chinesas e, ainda, prestam certos auxílios a esses imigrantes. Os Tongs, de modo diferente das tríades, operam de forma pública, ${ }^{19}$ como organizaçóes sociais, e seu objetivo é ajudar a comunidade (Lo e Kwok, 2013b).

De modo similar aos Tongs, os Snakeheads (Cabeças de Serpente) são organizaçóes que operam dentro da China, com atuação específica na logística transnacional de imigrantes chineses para países ocidentais, especialmente para os Estados Unidos. Esses grupos, apesar de serem organizados de acor- 
do com uma hierarquia definida, operam em uma estrutura bastante complexa, na qual a informação é compartimentada, ou seja, ninguém da organização sabe todos os detalhes da operação, o que dificulta as tentativas de rastreio e a desarticulação do grupo. Os líderes da organização possuem suas bases nos países de destino e, em geral, cidadania permanente, enquanto os recrutadores e transportadores operam a partir da China. Com isso, cada integrante sabe apenas o que lhe é pertinente saber no trecho pelo qual é responsável (Zhang e Chin, 2002).

De acordo com o que foi discutido com as autoridades e os acadêmicos chineses, há ainda outras organizaçóes que atuam dentro da China, em regióes diferentes. Contudo, existe uma enorme carência de material e bibliografia mais detalhada sobre elas. De fato, há uma quantidade maior de referência bibliográfica sobre as tríades, os Tongs e os Snakeheads, pois são mais conhecidos publicamente, uma vez que operam em territórios de língua inglesa, o que facilita a abordagem e a elaboração de relatórios sobre essas organizaçôes, em virtude do contato direto com norte-americanos britânicos e outros europeus. Nesse sentido, é de grande dificuldade precisar e estabelecer o funcionamento e as características de outras sociedades secretas dentro da China continental por causa da falta de bibliografia em língua inglesa ou mesmo de acadêmicos chineses que falem inglês, ou de acadêmicos não chineses que falem e leiam mandarim ou outros dialetos locais.

\section{Consideraçóes finais}

Conhecer a forma estrutural e organizacional, a característica antropológica e a limitação geográfica das tríades - uma vez que elas precisam e usam seus vínculos com a comunidade no local em que atuam - é suficiente para desacreditar não só boa parte do imaginário popular, como também a comparação que tanto se faz entre as tríades com a Yakuza, as máfias italiana ou russa, que possuem estruturas, atuação, organização e relação com o domínio espacial completamente diferentes entre si.

As diversas informaçóes equivocadas, obtidas das mais variadas fontes, por interessados e pesqui- sadores sobre o crime organizado, difundiram ideias falsas e conclusões errôneas sobre o tema. As tríades, conforme esta análise, são um fenômeno que tem sua atuação em uma área específica, no que diz respeito ao espaço geográfico.

Foi possível constatar também que na China continental há outros grupos criminosos e sociedades secretas, cujas origens e modos de atuação são bem diferentes das tríades. Desse modo, o termo "tríades chinesas" é algo que náo pode ser estendido a todos os grupos criminosos compostos por chineses, pelo fato de que a composição das tríades não é feita inteiramente por pessoas ligadas ao crime, mas por uma extensa rede de contatos, os quais colaboram entre si, buscando vantagens financeiras.

Esse é outro fator que diferencia as tríades dos grupos da Yakuza, pois as organizações japonesas possuem um vínculo profundo com questôes políticas. Com exceção de Taiwan (dada a participação das tríades na formação do Estado taiwanês e a política como uma forma de sobrevivência, em razão das tentativas de criminalização que sofreram na ilha), trata-se de um comportamento evitado pelas tríades, a fim de prevenir atenção desnecessária para seus negócios.

A generalização do termo "tríades" pode resultar em graves erros, comprometendo tanto as pesquisas científicas quanto os relatórios de autoridades, não apenas por uma questão de dialética ou de mero jogo palavras, mas porque pode induzir a análises metodológicas e operacionais equivocadas, tendo em vista a especificidade na forma com que cada organização conduz seus negócios, além da delimitação da abrangência de suas operaçóes, tanto no aspecto geográfico quanto no social e político.

Pelas análises realizadas, foi possível observar casos em que pessoas da colônia chinesa no Brasil rogavam para si a condição de serem membros de tríades, a fim de tirarem proveito e assediarem outros membros da comunidade, sem que fossem, de fato, integrantes de qualquer um dos vários grupos das tríades. Uma abordagem adequada afetaria significativamente sua reputação e capacidade de assédio sobre a comunidade, ao revelar que atuavam por si sós e não como membros de uma organização maior. 
Outra casuística que tem sido atribuída, de forma errônea, à ação de tríades no Brasil são as execuçôes e sequestros de pessoas da comunidade chinesa. É mais provável que sejam grupos criminosos provenientes da província de Fujian, sem qualquer ligação direta com as tríades. Esses grupos utilizam esquadrōes especializados em operaçóes-relâmpago ${ }^{20}$ no além-mar, compostos geralmente por três ou até seis integrantes, que chegam ao Brasil ou a algum país vizinho, ${ }^{21}$ executam sua missão e partem em dias ou até mesmo horas para outro local, enquanto as autoridades iniciam as investigaçóes sobre o caso.

Por fim, é importante ressaltar que essas sociedades secretas são extremamente flexíveis e adaptáveis. Nesse sentido, novas formas de atuação, organização e/ou estrutura poderão ser observadas, principalmente, em virtude do nível de repressão que elas sofrem em diferentes momentos. A habilidade de sobrevivência desses grupos reside, principalmente, na capacidade de adaptação, sempre em conformidade com o ambiente em que estão inseridas, estabelecendo-se no limiar entre a ilegalidade e a legalidade e, acima de tudo, necessitando da cooperação das comunidades locais onde atuam e da proteção de autoridades que eles conseguem cooptar.

\section{Notas}

1 Não é difícil achar mençôes tanto de autoridades públicas como da imprensa que insistem em dizer que as tríades são a máfia chinesa: "Os sequestradores são imigrantes membros das tríades - como é conhecida a máfia chinesa em alusão ao símbolo em forma de triângulo adotado". Além de se tratar de duas associaçóes diferentes, o nome náo tem nada a ver com um símbolo de triangulo. Ver http://g1.globo.com/ sao-paulo/noticia/2015/07/prisao-de-4-chineses-faz-policia-de-sp-retomar-investigacao-sobre-mafia. html, consultado em 21/10/2016.

2 Antes do estágio realizado na University of Hong Kong, outro estágio havia sigo realizado nos Estados Unidos, na Virginia Commonwealth University. A pesquisa realizada nessa universidade também teve como base o levantamento bibliográfico e as entrevistas, seguindo a mesma metodologia, pela qual foi possível coletar dados que seriam utilizados na presente pesquisa.
3 Apesar de sua derrota, a revolta dos Turbantes Amarelos foi um dos marcos que sinalizou o fim da Dinastia Han, em 184 d.C., sendo esta uma insurgência camponesa liderada por monges taoístas. Para mais detalhes, ver Ropp (2010, p. 36).

4 Há divergências bibliográficas sobre se a sociedade Tiandihui seria apenas ligada às tríades ou se seria a sua origem. Não há consenso entre os autores pesquisados.

5 Algumas das tríades aceitaram lutar ao lado dos japoneses, algumas resistiram e lutaram contra em forma de guerrilha, ao passo que outras preferiram ficar neutras.

6 Há discussões recentes que apontam uma gradual e lenta imigração dessas tríades de volta para a China continental a partir das cidades da província de Guangdong (Lo, 2009; Lo e Kwok, 2012).

7 Principalmente as facçôes criminosas da China continental, as quais constituem outras sociedades e organizações secretas de origem e características diferentes.

8 Essa característica é complexa e confusa, pois, em diversas legislaçóes, tal atividade é considerada como tráfico de influência e, portanto, também criminosa. Porém, em grande parte dos países do Sudeste e do Sul da Ásia, essa é uma característica cultural e de mercado básica, nem mesmo sendo limitada às tríades chinesas. No caso da China, isso pode ser remetido ao conceito de guanxi, expressáo sem tradução literal que poderia ser, de certa forma, interpretada como obrigaçóes de reciprocidade. Para mais informaçóes, ver Lo (2010).

9 Chiang Kai-Shek por sua vez era uma das lideranças da "Gangue Verde" (Qingbang), outra Sociedade Secreta que teve importante papel durante a Segunda Guerra Mundial e Guerra Civil Chinesa. Contudo, após a vitória comunista na China continental e a fuga das forças de Kai-Shek para Taiwan, os últimos elementos da Gangue Verde se misturaram com as tríades taiwanesas (Taylor, 2009, p. 31).

10 Mao Tsé Tung também recrutou as sociedades secretas para auxiliarem-no contra as forças japonesas e, posteriormente, contra as forças nacionalistas. Originalmente, ele via nessas organizaçóes um embrião revolucionário semelhante ao ideal comunista.

11 A Primeira Guerra do Ópio ocorreu entre 1839 e 1842, e a Segunda Guerra do Ópio, de 1856 a 1860.

12 O consumo do ópio foi liberado na China, mas proibido na Inglaterra.

$13 \mathrm{Na}$ época, o consumo desenfreado de ópio na China criou diversas e enormes zonas de consumo livre nas principais cidades chinesas. De acordo com observa- 
dores da época, em várias ruas de Shanghai e Pequim, a entrada era praticamente impossível devido aos altos índices de criminalidade.

14 A divisão antiterrorista em Hong Kong, treinado pelo Serviço Aéreo Especial (SAS, na sigla original), a elite da forças armadas britânicas, era mantida em segredo absoluto, sendo reservada para algum eventual caso de ataque terrorista. Contudo, tornou-se conhecida ao ser usada nas operaçóes antitríades.

15 Algumas cerimônias duram até sete horas.

16 Filmes como Infernal affairs (Hong Kong, 2002) ou documentários como Gangland: dead triangle (History Channel, 2008) mostram tais cerimônias como sendo contemporâneas.

17 Abadinsky usa como referência Booth, que havia escrito seu livro no final dos anos de 1990. Ou seja, antes de ficarem claras as transformaçôes ocorridas em Hong Kong após seu retorno para a China, bem como antes de diversas repressóes legais durante os anos de 2000 que afetaram a forma das tríades.

18 O termo "ocidentais" está sendo usado como referência a qualquer pessoa oriunda do Ocidente, como europeus, norte-americanos e latino-americanos.

19 Principalmente nos Estados Unidos, na Inglaterra e no Canadá.

20 Exemplos de sequestros, extorsão e assassinatos no Brasil são facilmente encontrados na internet, em sites de notícia, e em quase todos os casos há mençôes das autoridades públicas que erroneamente atribuem os ocorridos à ação das tríades.

21 Isso não ocorre apenas no Brasil.

\section{BIBLIOGRAFIA}

ABADINSKY, HOWARD. (2010), Organized crime. 9 ed. Belmont (CA), Wadsworth Cengage Learning.

ALBANESE, Jay S. (2007), Organized crime in our times. 5 ed. Newark (NJ), LexisNexis.

BOOTH, Martin. (1999), The Dragon Syndicates: the global phenomenon of the triads. Londres, Doubleday.

CHESNEAUX, Jean. (1971), Secret societies in China: in the nineteenth and twentieth centuries. Ann Arbor (MI), University of Michigan Press.

CHIN, Ko-Lin. (2003), Heijin: organized crime, business and politics in Taiwan. Nova York, M. E. Sharpe.

CHU, Yu Kong. (2005), "Hong Kong triads after 1997”. Trends in Organized Crime, 8 (3): 5-12.

COMBER, Leon. (2009), The triads: Chinese secret societies in 1950s Malaya and Singapore. Cingapura, Talisman/Singapore Heritage Society.

GOOGLE MAPS. (2016). Disponível em www.Google.Com.Br/maps/@5.3576467, 118.6230255,5z, consultado em 5/5/2016.

GILES, Herbert A. ([1880] 2000), Freemasonry in China. Londres, Routledge.

HAAR, Barend J. ter. (1998), Ritual and mythology of the Chinese triads: creating an identity. Leiden, Brill Academic.

KAPLAN, David. E. (1992), Fires of the dragon: politics, murder, and the Kuomintang. Londres, Maxwell Macmillan.

LAIDLER, Karen A. J.; HODSON, David \& TRAVER, Harold. (2000), The Hong Kong drug market: a report for Unicri, The UNDCP global study in illicit drug markets. Hong Kong, Centre for Criminology/University of Hong Kong.

LINTNER, Bertil. (2002), Blood brothers: crime, business and politics in Asia. Chiang Mai, Silkworm.

LIU, Benjamin T. M. (2003), The Hong Kong triad societies: before and after the 1997 change-over. Hong Kong, Net e-Publishing Limited.

LO, Sonny Shiu-Hing. (2009), The politics of cross border crime in greater China: case studies of mainland China, Hong Kong and Macao. Nova York, East Gate Book.

LO, T. Wing. (2010), "Beyond social capital: triad organized crime in Hong Kong and China". British Journal of Criminology, 50 (5): 851-872. . \& KWOK, Sharon Ingrid. (2012), "How triad societies respond to socioeconomic change: in traditional organized crime in the modern world". Studies of Organized Crime, 11: 67-89.

. (2013a), "Anti-triad legislations in Hong Kong: Issues, problems and development". Trends in Organized Crime, 16 (1): 74-94.

. (2013b), "Chinese triads and tongs", in G. Bruinsma e D. Weisburd (eds.), Encyclopedia of 
Criminology and Criminal Justice, Nova York, Springer.

NASH, Jay Robert. (2004), The great pictorial history of world crime. Lanham, MD, Scarecrow.

STANTON, William. ([1900] 2000) The triad society or heaven and earth association. Londres, Routledge.

ROPP, Paul S. (2010), China in World History. Oxford, University Press.

TAYLOR, Jay. (2009), The generalissimo: Chiang Kai-shek and the struggle for modern China. Belknap press of Harvard University Press.

WARD, John Sebastian Marlowe ([1925] 2000). The Hung Society or The Society of Heaven and Earth. Londres, Routledge.

ZHANG, Sheldon \& CHIN, Ko-Lin. (2002), "Enter the dragon: inside Chinese human smuggling organizations". Criminology, 40 (4): 737-768. 


\section{AS TRÍADES E AS SOCIEDADES SECRETAS NA CHINA: ENTRE O MITO E A DESMISTIFICAÇÃO}

\section{De Leon Petta}

Palavras-chave: Crime organizado; Tríades chinesas; Sociedades secretas; Sudeste Asiático; China.

O presente artigo é o resultado da pesquisa de campo sobre as tríades e o crime organizado chinês, realizada em Hong Kong. Baseia-se em bibliografia sugerida por pesquisadores de universidades locais, entrevistas com pesquisadores, jornalistas e membros atuantes na segurança pública, e em observação de campo. Analiso as raízes simbólicas e as origens históricas das tríades chinesas procurando diferenciá-la da ideia de crime organizado convencional. Com uma perspectiva interdisciplinar, procuro descontruir aspectos exagerados, irreais e folclóricos, bem como expor as características atuais desse tipo de organização.

\section{THE TRIADS AND THE SECRET SOCIETIES IN CHINA: BETWEEN MYTH AND DEMYSTIFICATION}

De Leon Petta

Keywords: Organized crime; Chinese triads; Secret societies; Southeast Asia; China

This article is the result of the field research about the Triads and the Chinese organized crime, made in Hong Kong. It is based on local literature, suggested by researchers from local universities, also interviews with researchers, journalists, both former and current members of public security, and personal observation in the field research about the activities of these organizations. The focus is to address the symbolic roots and historical origins of the Chinese Triads as well as its structure and functioning, then differentiating it from the conventional idea of organized crime. Aiming an analysis interdisciplinary of the object, I use the geography, history and social sciences to deconstruct exaggerated, unrealistic and folkloric aspects and expose the current characteristics of this organization.

\section{LES TRIADES ET LES SOCIÉTÉS SECRÈTES EN CHINE: ENTRE MYTHE ET DÉMYSTIFICATION}

\author{
De Leon Petta
}

Mots clés: Crime organisé; Triades chinoises; Sociétés secrètes; Sud-est Asiatique; Chine

Cet article est le résultat de recherches sur le terrain à propos des triades et du crime organisé chinois, qui ont eu lieu à Hong Kong. Il se base sur la bibliographie proposée par les chercheurs des universités locales, des entretiens avec des chercheurs, des journalistes et des membres actifs de la sécurité publique, ainsi que de l'observation sur le terrain. Nous analysons les racines symboliques et les origines historiques des triades chinoises tout en tentant de les différencier de l'idée conventionnelle de crime organisé. Suivant une perspective interdisciplinaire, nous avons tenté de déconstruire des aspects exagérés, irréels et folkloriques, ainsi que d'exposer les caractéristiques actuelles de ce type d'organisation. 